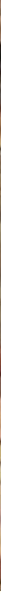

\title{
Las techumbres del palacio renacentista de los Pinelo en Sevilla: conservación y restauración en el siglo XX
}

\author{
Pedro Barrero-Ortega, Antonio Gámiz-Gordo
}

\begin{abstract}
Resumen: Esta investigación analiza por primera vez las singulares y poco conocidas techumbres del palacio renacentista Casa de los Pinelo en Sevilla. Tras sufrir importantes transformaciones al convertirse en Pensión Don Marcos (1885-1964), fue declarado monumento histórico (1954) y expropiado por el Ayuntamiento de Sevilla (1964). Entonces se acometieron profundas intervenciones y restauraciones por los arquitectos Jesús Gómez-Millán (1967-1971) y Rafael Manzano Martos (1969-1981) para alojar las sedes de las Reales Academias Sevillanas de Buenas Letras y de Bellas Artes, uso que aún mantiene. Siguiendo un excepcional texto de 1542, transcrito para este trabajo, se ofrece un recorrido inédito por las distintas techumbres, hoy conservadas, transformadas o desaparecidas, ratificando su datación. Se aportan plantas generales y fotografías del estado actual, junto a datos inéditos sobre intervenciones documentadas que facilitan la valoración de su rico y diverso conjunto.
\end{abstract}

Palabras clave: techumbres, techos, palacio, Renacimiento, Sevilla, alfarje, artesonado, dibujo

\section{The roofs and ceilings of the Renaissance Palace of Pinelo in Seville: conservation and restoration in the 20th century}

\begin{abstract}
This study analyzes for the first time the unique, unexplored roofs and ceilings of the Renaissance palace Casa de los Pinelo in Seville. After deep transformations to become the Pension Don Marcos (1885-1964), the building was classified as heritage site (1954) and hence expropriated by the City Council (1964). Thenceforth, deep interventions and modifications were executed by architects Jesús Gómez-Millán (1967-1971) and Rafael Manzano Martos (1969-1981) so the building may host the headquarters of the Royal Academies of Belles Lettres and Fine Arts of Seville. Starting from an exceptional text dated in 1542 and transcribed for this purpose, this article offers a singular journey across the different types of roofs -nowadays preserved, transformed, or lost- documenting their dates. Modern floor plans and photographs together with unpublished data upon various alterations are also provided in order to facilitate the appreciation of this rich architectural complex.
\end{abstract}

Keyword: roofs, ceilings, palace, Renaissance, Seville, alfarje, wooden ceiling, drawing

\begin{abstract}
Os telhados do palácio renascentista do Pinelo em Sevilha: conservação e restauro no século XX
Resumo: Esta investigação analisa pela primeira vez as coberturas únicas e pouco conhecidas do palácio renascentista Casa de los Pinelo em Sevilha. Após sofrer importantes transformações ao se converter na Pensión Don Marcos (1885-1964), foi declarado monumento histórico (1954) e expropriado pela Câmara Municipal de Sevilha (1964). Em seguida, profundas intervenções e restauros foram realizados pelos arquitetos Jesús Gómez-Millán (1967-1971) e Rafael Manzano Martos (1969-1981) para abrigar a sede das Real Academias Sevilhanas de Boas Letras e Belas-Artes, uso que ainda se mantém. Na sequência de um texto excecional de 1542, transcrito para este trabalho, oferece-se um passeio inédito pelas diferentes coberturas, hoje conservadas, transformadas ou desaparecidas, confirmando a sua datação. Planos gerais e fotografias do estado atual são fornecidos, juntamente com dados não publicados sobre intervenções documentadas que facilitam a avaliação de seu rico e diversificado conjunto.
\end{abstract}

Palavras-chave: telhados, tetos, palácio, Renascimento, Sevilha, alfarge, teto de madeira, desenho 


\section{Consideraciones generales}

Según el diccionario de la Real Academia Española la palabra techumbre equivale a techo, o sea, "parte superior de un edificio", o "conjunto de la estructura y elementos de un techo". Normalmente se denomina techo al paramento superior del interior de una habitación, pero si tiene cierta altura o complejidad suele llamarse, de forma genérica, techumbre.

En edificios históricos son frecuentes las techumbres de madera conocidas como alfarjes o artesonados. Según Torres Balbás "...alfarje se llamaba en la Edad Media y aún en los siglos posteriores, [...] al techo holladero y, por tanto, horizontal. [...] Yerran pues los que ahora llaman -y son muchedumbre- alfarjes a las armaduras de par y nudillo de artesón" (Torres Balbás 1944). Según el diccionario de la Real Academia Española los artesonados son "techos, armaduras o bóvedas con artesones [...] y con forma de artesa invertida". En todo caso, puede considerarse que la palabra techumbres engloba tanto alfarjes y forjados de piso, como artesonados y armaduras de cubierta, cuyas vigas incorporan con frecuencia adornos entre ellas.

Existen destacados ejemplos de alfarjes y artesonados en la arquitectura hispanomusulmana, mudéjar y renacentista
(Nuere, Manzano, 2010). Su configuración resulta muy diversa en monumentos como el Real Alcázar de Sevilla, la Alhambra de Granada, el palacio de la Aljafería de Zaragoza o en otros muchos edificios históricos de nuestra geografía peninsular (Rafols 1926) y también de América (López 2012).

Un caso poco conocido son las techumbres del palacio renacentista de los Pinelo en Sevilla, objeto de este estudio. Debe considerarse que no son muchas las investigaciones sobre la arquitectura de dicho palacio, pudiendo destacarse dos artículos de Rafael Manzano (Manzano 1997 y 2019), un libro de Teodoro Falcón (Falcón 2006), una tesis doctoral y un artículo de Pedro Barrero (Barrero, 2017a y 2017b) más dos recientes textos de Pedro Barrero y Antonio Gámiz (Barrero, Gámiz 2020a y 2020b).

Esta investigación es la primera sobre el singular conjunto de techumbres de este palacio renacentista. Tras haber dibujado todas y cada una de ellas [figuras 1 a y b] se han revisado datos históricos y a partir de un texto de 1542 se ofrece un recorrido por las distintas techumbres conservadas, transformadas o desaparecidas. Además se aportan fotografías actuales y se analizan destacadas intervenciones o restauraciones del siglo XX que les afectaron.

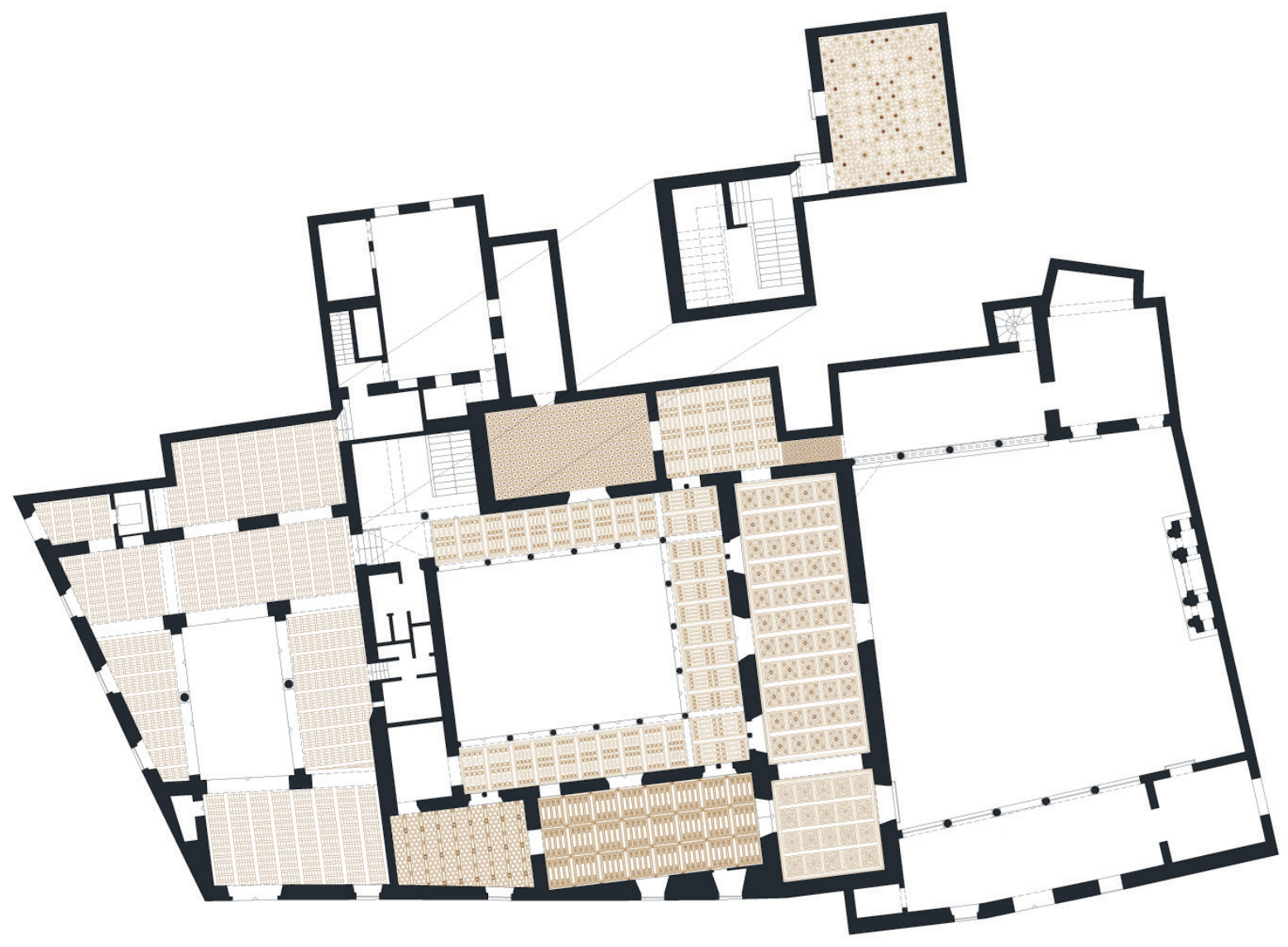

Figura 1 a).- Planta general de techumbres: Estado actual planta baja y entreplanta. Dibujo propio. 


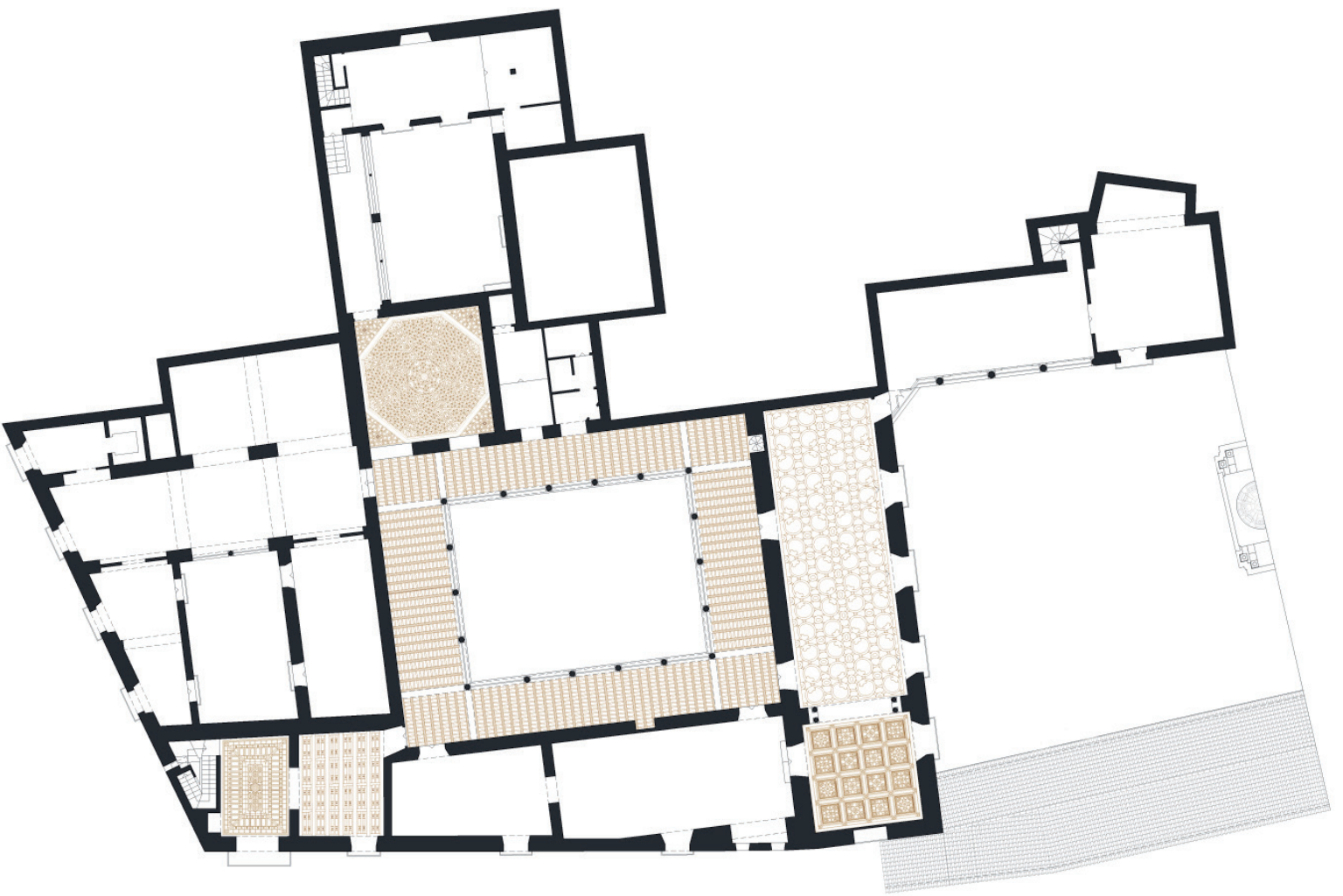

Figura 1b).- Planta general de techumbres: Estado actual planta alta. Dibujo propio.

El palacio de los Pinelo fue construido hacia 1500 por una familia de prósperos comerciantes genoveses que tuvieron un destacado papel en las relaciones con América y en la Casa de la Contratación de Sevilla. Se localiza cerca de la catedral hispalense, en un entramado urbano de origen medieval, en la calle Abades esquina con calle Segovias. La altana o torre-mirador que conforma el encuentro de fachadas del edificio sería la primera construida en Sevilla bajo la influencia de las villas del renacimiento italiano.

Su ordenación general se conforma mediante tres patios yuxtapuestos, según un esquema frecuente en la arquitectura medieval hispana (Almagro, Manzano, 2008): uno de acceso o apeadero; otro principal o de honor; y el tercero o jardín que ocupa el espacio libre hasta las medianeras. El patio principal y sus arquerías se enmarcan dentro de una secuencia evolutiva de grandes casas palaciegas sevillanas de gran interés arquitectónico, artístico e histórico: el palacio del Rey Don Pedro del Real Alcázar, la Casa de Pilatos, el palacio de Las Dueñas, este de los Pinelo y el de Mañara.

\section{—Un apeo y deslinde de 1542}

En 1523 la familia Pinelo vendió el palacio al Cabildo Catedralicio, que en 1542 promovió la redacción de un apeo y deslinde para la Fábrica de la Santa Iglesia de Sevilla que tiene un total de dieciocho páginas ${ }^{1}$. Debe considerarse que las instituciones religiosas de aquel tiempo reunieron un cuantioso patrimonio inmobiliario, gestionado con el apoyo de estos documentos-los apeos- redactados por alarifes que aportaban minuciosos datos sobre los inmuebles descritos, incluyendo medidas (Núñez 2018).

Se ha transcrito el texto completo de dicho apeo, que aporta una descripción de techumbres crucial para su identificación y datación, dadas las importantes alteraciones posteriores del palacio. Por ello, fragmentos del citado texto encabezan próximos apartados en los que se recorren sus diversas dependencias.

\section{- Las transformaciones y reparaciones del edificio como Pen- sión Don Marcos (1885-1964)}

No se conocen datos significativos sobre transformaciones del palacio hasta después de su desamortización y compraventa en 1870, cuando fue convertido en Pensión Don Marcos hacia 1885. Entonces fue redistribuido para obtener setenta y cinco habitaciones, según planos del proyecto de expropiación de 1964 después mencionados (Barrero, Gámiz 2020b). En el Archivo Municipal de Sevilla se han revisado todos los expedientes de obras en la calle Abades entre 1870 y 1964, constatándose que no se tramitó un proyecto unitario para adecuar el palacio a su nuevo uso hotelero. Los expedientes municipales de obras entre 1872 y 1905 reflejan solo modificaciones en huecos de fachadas 
que sin duda responderían a una profunda redistribución interna.

Además hubo intervenciones menores para la conservación del edificio. Así, el arquitecto Juan Talavera y de la Vega solicitaba el 26 de mayo de 1905 permiso para reparar el alero del tejado². Otros expedientes de obras posteriores, entre 1934 y 1946 , reflejaban su mal estado de conservación. Un escrito de 1 de diciembre de 1942 del arquitecto municipal Ramón Balbuena Huertas hablaba de filtraciones de aguas, lo que hace pensar en la progresiva degradación del edificio ${ }^{3}$, que se constata en posteriores expedientes de obras que tratarían de evitar males mayores. Todo ello justificaría las importantes intervenciones del último tercio del siglo XX y la pérdida de importantes techumbres de planta alta.

\section{— Las intervenciones de Jesús Gómez-Millán (1967-1971)}

En 1954 la Casa de los Pinelo fue declarada monumento histórico-artístico. Para ello se elaboró un plano de planta con la distribución de la Pensión Don Marcos, que es muy similar a la reflejada en el proyecto de expropiación del Ayuntamiento de Sevilla del arquitecto municipal Jesús Gómez-Millán Millán (Sevilla 1916-1984) en 1964.

Tras la expropiación hubo importantes obras de promoción municipal, dirigidas por dicho arquitecto entre 1967 y 1971. Se han revisado todos los expedientes disponibles en el Archivo Municipal de Sevilla, en nueve proyectos o fases ${ }^{4}$. Las cuatro primeras fases se refieren a cubiertas en distintas zonas, incluyendo las galerías altas del patio de honor y la elevación de la caja de su escalera principal.

\section{- Las restauraciones de Rafael Manzano Martos (1969-1981)}

RafaelManzanoMartos (Cádiz, 1936) trabajó comoarquitecto del Servicio de Defensa del Patrimonio Artístico Nacional de la Dirección General de Bellas Artes entre 1962 y 1982; fue Director-Conservador y Alcaide de los Reales Alcázares de Sevilla, de 1970 a 1988; y desde 1968 Catedrático en la E.T.S. de Arquitectura de Sevilla. En 2010 recibió el premio Richard H. Driehaus, en Chicago; y en 2012 se instituyó el premio Rafael Manzano Martos de Arquitectura Clásica y Restauración de Monumentos, patrocinado por prestigiosas instituciones de Estados Unidos y España.

Sus obras en el palacio de los Pinelo fueron promovidas por la Dirección General de Bellas Artes a través de sucesivos proyectos. El primero -según datos del Archivo General de la Administración- en febrero de $1969^{5}$, para Casa-Museo de la ciudad, incluía un diagnóstico del edificio y se centraba en la restauración del torreón-mirador. En el archivo privado de Rafael Manzano se ha consultado un proyecto de restauración para Casa-Museo de la ciudad de 1970, que no se encuentra en dicho Archivo. Planteaba la consolidación de los forjados conservados, reconstruyendo con hormigón aquellos cuya decoración había desaparecido, colgando de estructura metálica los artesonados sin adecuadas condiciones resistentes.

Otro proyecto de marzo de 1972, redactado cuando Gómez-Millán ya no actuaba en el palacio, se refería a un nuevo uso: sede de las Reales Academias de Buenas Letras y Bellas Artes de Sevilla ${ }^{6}$. Preveía completar la consolidación de forjados de las cubiertas. En agosto de 1973 se redactó un proyecto $^{7}$ para zonas comunes pendientes; al que seguiría el de octubre de $1975^{8}$, centrado en la restauración de artesonados y carpinterías. Hubo un último proyecto en noviembre de $1978^{9}$.

Se han revisado todos los documentos citados, y en el archivo privado del Rafael Manzano se han consultado certificaciones de obras, fotografías, contratos de servicios profesionales, así como actas de replanteo y otros documentos. Todo ello arroja luz en el recorrido inédito ofrecido a continuación sobre las distintas techumbres, a partir del apeo de 1542.

\section{Techumbres en planta baja}

\section{- Apeadero}

"[...] la dicha casa puerta [...] es doblado al mismo tamaño sobre diez vigas guarneçidas de desvanes, e sus alfarxias, e azulejos por tabla azules e blancos. [...] Yten desta casa puerta entramos a un arco a dos hazes un reçebimiento [...] es doblado al mismo tamaño sobre ocho vigas e sus alfarxias. Yten deste reçebimiento entramos a un palacio [...] doblado al mismo tamaño, sobre seis vigas guarneçidas de desvanes. E sus alfarxias e sus ladrillos por tabla de junto".

Comenzaba el apeo del siglo XVI describiendo los techos del acceso al palacio, junto a dependencias en el patio apeadero, denominadas casapuerta, recibimientos y caballerizas. Estaban resueltos, como hoy, con vigas de madera, alfarjías y azulejos por tabla, o sea, sustituyendo la tablazón por piezas cerámicas. Después se describían las crujías junto a dicho patio destinadas a las caballerizas y sus techos también resueltos con ladrillo por tabla:

"Yten de este dicho patio entramos a una caualleriza [...] doblado sobre quatro vigas e sus alfarxias e ladrillo por tabla e [...] un entresuelo sobre tres vigas e sus alfarxias e ladrillo por tabla tosco [...]. Yten deste dicho patio entramos en otra caualleriza que esta al rincon [...] doblado al mismo tamaño sobre çinco vigas e sus alfarxias e ladrillo por tabla de junto".

Debe recordarse que cuando el palacio se convirtió en pensión, se trasladó su acceso originario, que fue cegado al igual que los arcos y galerías del patio apeadero, para obtener el mayor número posible de habitaciones (Barrero Gámiz 2020b). Dichas particiones fueron eliminadas por el arquitecto Jesús Gómez-Millán. 
El proyecto de Rafael Manzano de 1970 contemplaba la consolidación de forjados de planta baja en las dependencias junto a este patio. La hoja 3 de sus mediciones describía el criterio técnico seguido, consistente en la sujeción del entramado de madera existente a una estructura metálica superior. Tras asegurarse la capacidad resistente, se restauró el entramado actual de madera con vigas, alfarjías y ladrillos por tabla vidriados, completado con la limpieza de vigas y restauración de pintura.

O sea, las actuales vigas de los entramados leñosos del apeadero son las preexistentes, saneadas, reparadas o sustituidas algunas por pérdida de sección, sobre todo en los apoyos hacia el patio, más castigadas por las aguas pluviales. Se restituyeron los ladrillos por tabla con distintas tonalidades y sobre ellos se dispuso una solería perdida de rasillas cerámicas hasta la cota del ala superior de los perfiles metálicos usados para la consolidación; más una capa de compresión de hormigón como base de la solería [figura 2].
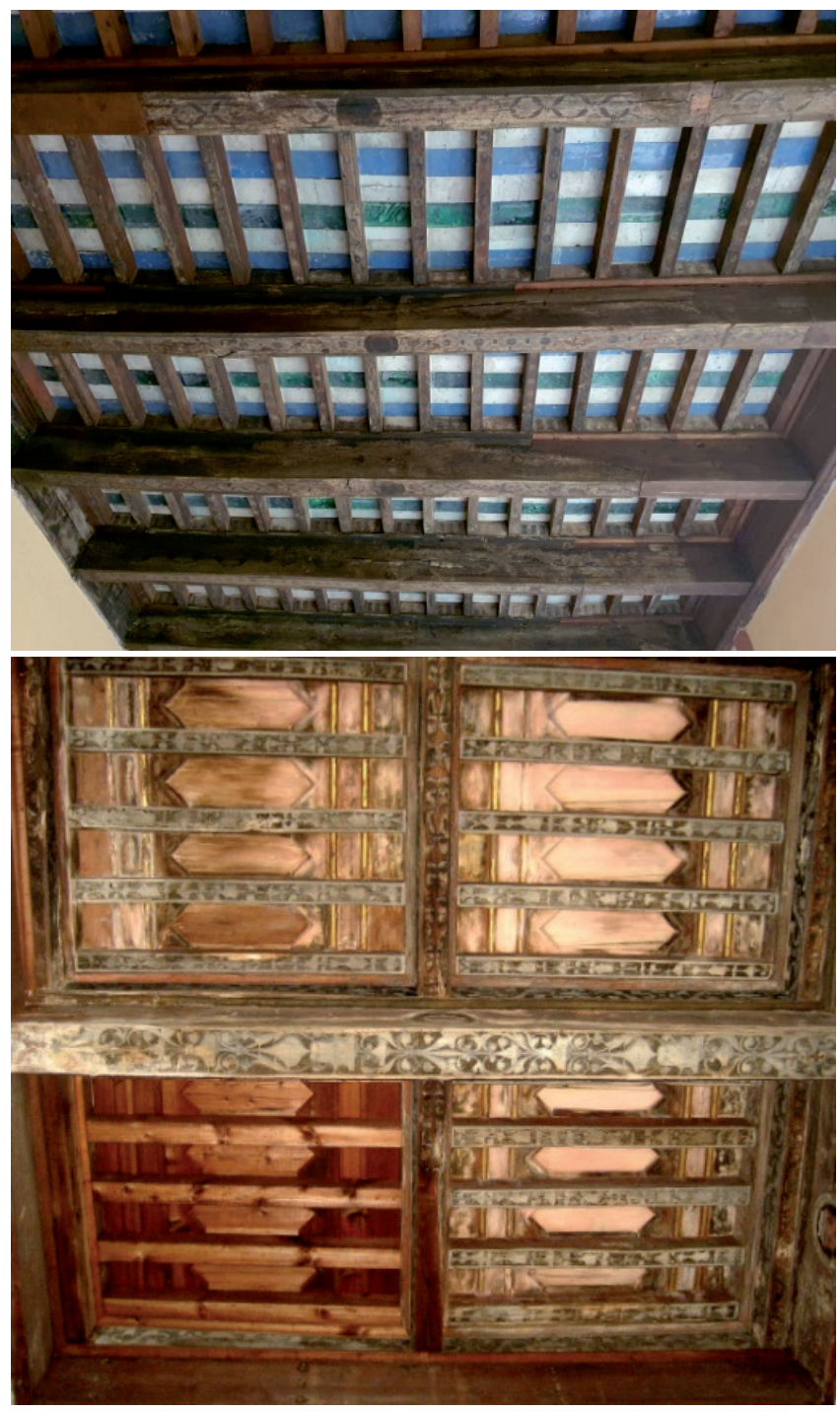

Figura 2.- Techumbre del patio Apeadero y alfarje galería patio principal. Fotografías propias.

\section{- Galerías del patio principal}

"Yten deste dicho azaguan entramos en un portal [...] doblado al mismo tamaño sobre diez vigas guarnecidas de desvanes e pintadas e sus almoxairas e un suelo de media guarniçion con sus copas cerradas digo doradas con su arocabe a la redonda"

Según la memoria del proyecto de Manzano de 1969, en la galería del patio se conservaban los admirables alfarjes de la planta baja, de fina decoración renacentista pintada, pero fue necesario desmontar el forjado para sustituir piezas deterioradas. Las cabezas de las vigas sin capacidad resistente se cortaron y se sustituyeron por otras de madera sana mediante unión atornillada con pletinas metálicas de perfil en U. También se sustituyó alguna alfarjía y su tablazón de madera, hoy reconocibles respecto a los originales conservados [figura 2].

Respecto a la galería de planta alta, el apeo de 1542 la describía de la siguiente forma:

"Yten subimos por la dicha escalera principal a los quatro corredores que caen los tres sobre los tres portales [...]. E lo alto es los tres tejados a un agua e tiene su saquiçami. Es desauados de molduras y el otro que cae delante la sala por donde entran a la huerta es doblado de açoteas sobre veinte vigas e sus alfarxias e ladrillo por tabla".

Dicha galería había sido tabicada en la Pensión Don Marcos para obtener mayor número de habitaciones (Barrero, Gámiz 2020b). Fue recuperada por el arquitecto Jesús Gómez Millán y en la tercera fase de sus obras se sustituyeron los forjados en mal estado por otros de hormigón y los techos se forraron con madera de una forma discreta y económica.

\section{- Sala de Revistas de la Real Academia de Buenas Letras y pasillo que conduce al jardín}

"Yten del portal primero entramos sobre mano ysquierda a una quadra [...] tiene una cinta de jeseria a la redonda [...] doblada al mismo tamaño sobre quatro vigas que estan guarneçidas de desvanes con sus copas doradas e lo otro tiene sus almoxaras e alfarxias con su media guarniçion e sus verdugos obrados e su arocabe de madera".

Esta techumbre, situada junto al patio principal, se sigue conservando -según el apeo- sobre cuatro vigas con arrocabe de madera y no se han documentado restauraciones destacables. [figura 3]

El apeo continúa describiendo el pasillo hacia la logia baja del jardín que hoy conserva su bóveda de artesones de yesería ochavados [figura 3]:

"Yten desta quadra entramos a un azaguan [...]e lo alto dello es de artesones de jesería ochauados". 

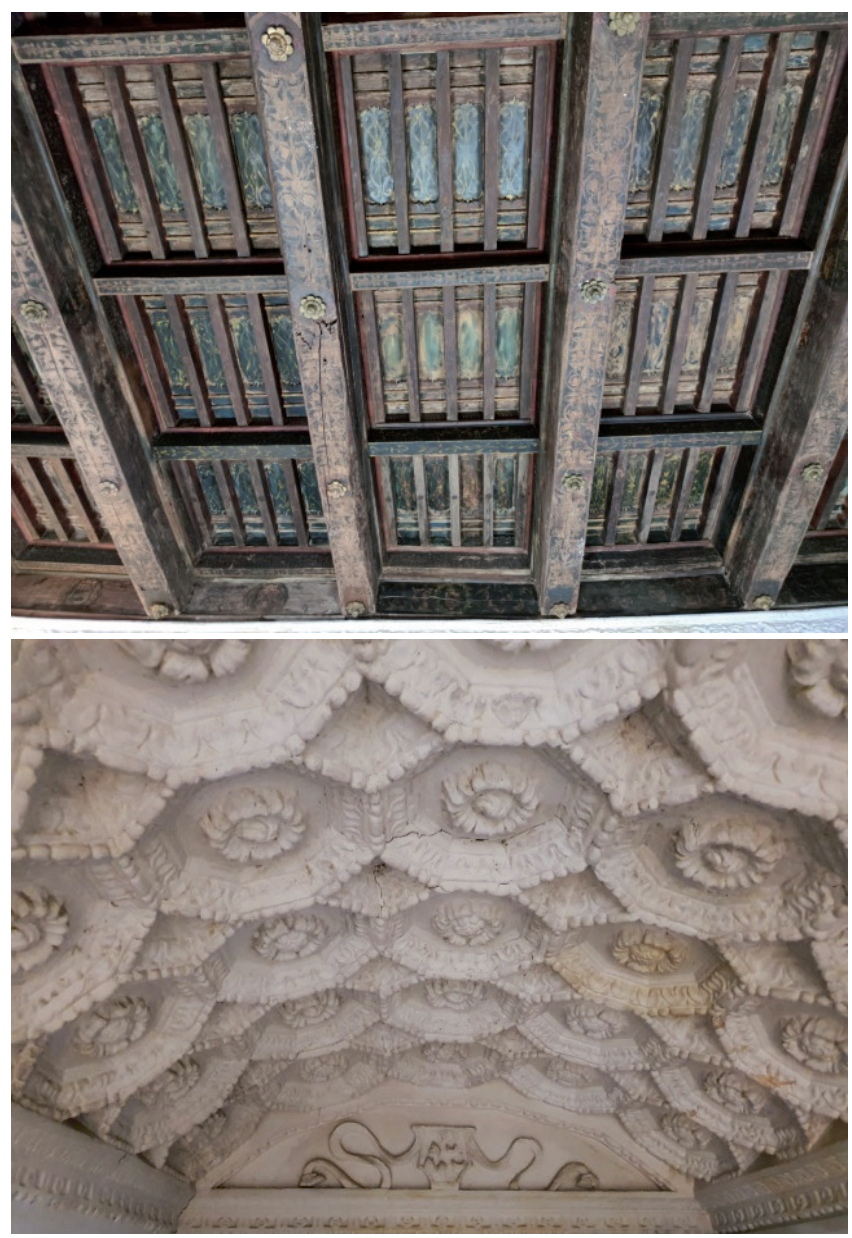

Figura 3.- Techumbre de la actual Sala de Revistas de la Real Academia de Buenas Letras. Bóveda del pasillo al jardín. Fotografías propias.
Su trazado se basó en la lámina LXXV vta. del Libro IV de Sebastián Serlio, una publicación que ejerció gran influencia en maestros de obra y arquitectos españoles (Cuesta 2017). Según el proyecto de Rafael Manzano de agosto de 1973, la actual Secretaría de la Real Academia de Buenas Letras, cercana al pasillo, había perdido su techo. La nueva artesa fue proyectada y construida por Manzano copiando los citados motivos renacentistas con octógonos y rombos alternos.

\section{- Salón de Actos de la Real Academia Sevillana de Buenas} Letras

"Yten del segundo portal entramos a una sala la qual [...] doblado al mismo tamaño la mitad sobre quatro vigas e sus alfarxias e ladrillo por tabla tosco e la otra mitad sobre quatro vigas todas guarneçidos de molduras dorados sobre quinze razimos e almocaraues dorados. E tiene diezyseis paños de lazo con sus çinco razimos todo pintado e dorado. E otra parte es sobre tres vigas de toscos e sus alfarxias e ladrillos por tabla toscos. E un arocabe de jeseria moldada"

Decía Rafael Manzano que se habían perdido los alfarjes de esta sala"de los que sólo quedaban las vigas maestras, siendo los fondos ataujerados que hoy vemos, con trazas de sabor mudéjar, obra ya de mi cosecha..." (Manzano,1997). Dichas obras se contemplaban en su proyecto de 1975: la partida 3.02 de las mediciones describía un artesonado "constituido por vigas de madera curada vieja formando casetones decorados con tema de lazo y piñas de mocárabes." [figura 4]. Según Falcón Márquez este importante techo reconstruido recuerda mucho al del salón del Pretorio de la Casa de Pilatos

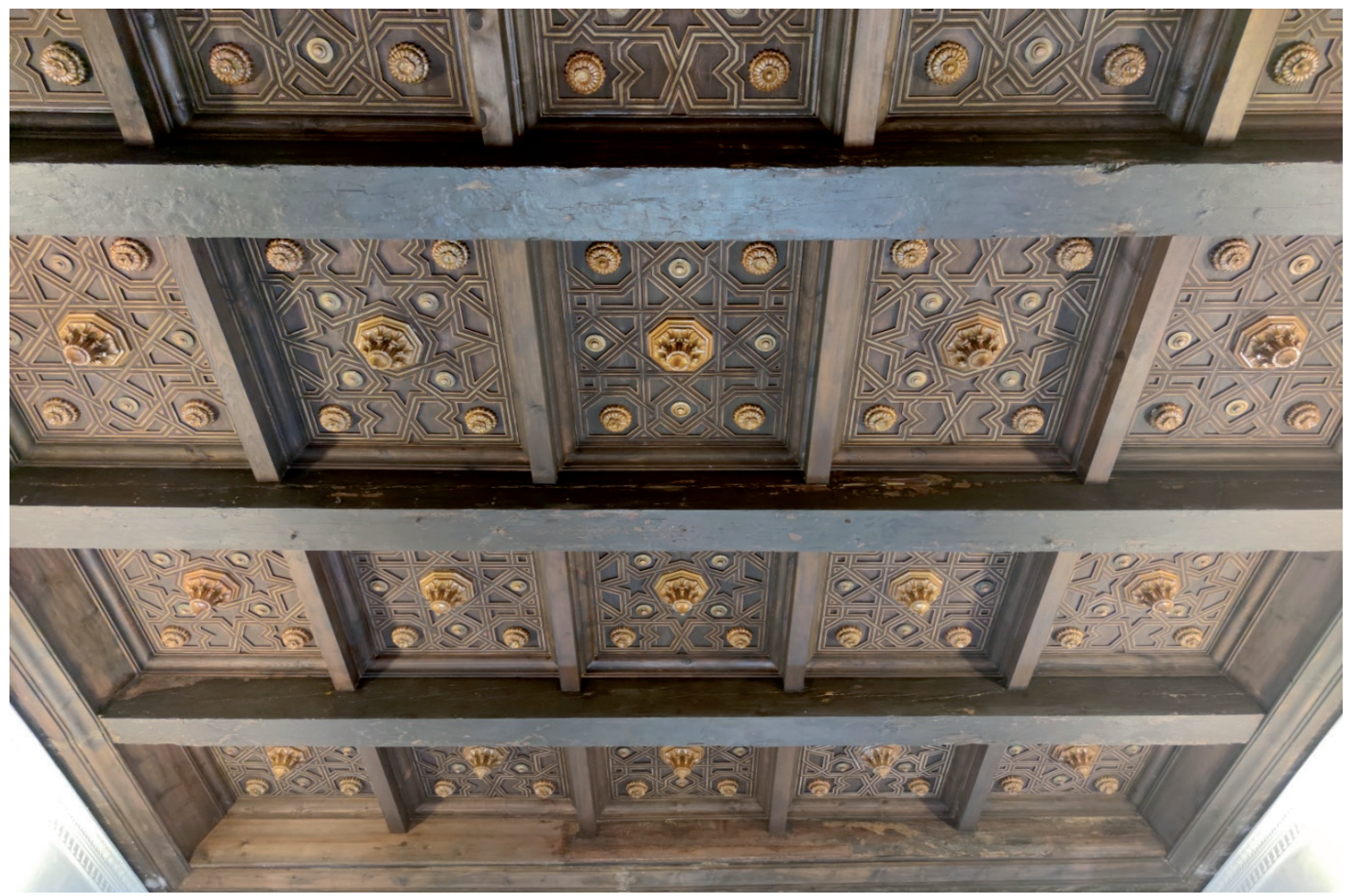

Figura 4.- Techumbre del Salón de Actos de Buenas Letras. Fotografía propia. 
en Sevilla, realizado por Andrés de Juara en 1536 (Falcón 2006).

- Salas de la actual biblioteca de la Real Academia de Buenas Letras

"Yten del tercero portal sobre la mano derecha entramos a una sala la qual tiene un arco de jeseria con sus medallas [...] doblada al mismo tamaño sobre siete pinos e sus almoxairas e su suelo de media guarnicion dorado con sus copas e razimos dorados".

Sigue el recorrido por la actual biblioteca de la Real Academia de Buenas Letras, donde no se han documentado restauraciones relevantes y se conserva el espléndido techo original descrito, con sus siete vigas [figura 5]. La biblioteca cuenta con un segundo cuerpo -cámara según el apeoque también conserva el artesonado original, pintado con racimos dorados, sin intervenciones documentadas. Se describe así:

"Yten desta sala entramos a una camara la qual tiene [...] doblado al mismo tamaño sobre siete [ocho] pinos guarneçidos de molduras e pintados con ocho pinos de artesones desauados con sus razimos dorados e su arocabe a la redonda pintados e tiene a la redonda dos varas en alto aforrado de azulejos".

\section{Techumbres escalera principal y entreplanta}

\section{- Artesonado de la escalera principal}

"Yten deste dicho reçebimiento entramos a un azaguan [...] doblado al mismo tamaño sobre una viga e sus alfarxias e su ladrillo por tabla de junto [...] Yten deste azaguan [...] esta el escalera principal que sube a lo alto, e lo alto della es de un tejado de una quadra ochauada a manera de media naranja tosco e sus alfarxias e ladrillo por tabla".

Tras el zaguán entre el apeadero y el patio de honor, aparece la escalera principal, que se cubría con una armadura leñosa ochavada hoy desaparecida, a manera de media naranja, con alfarjías y ladrillos por tabla.

Jesús Gómez-Millán elevó las cubiertas de la caja de escalera, a modo de castillete, en la cuarta fase de sus intervenciones.

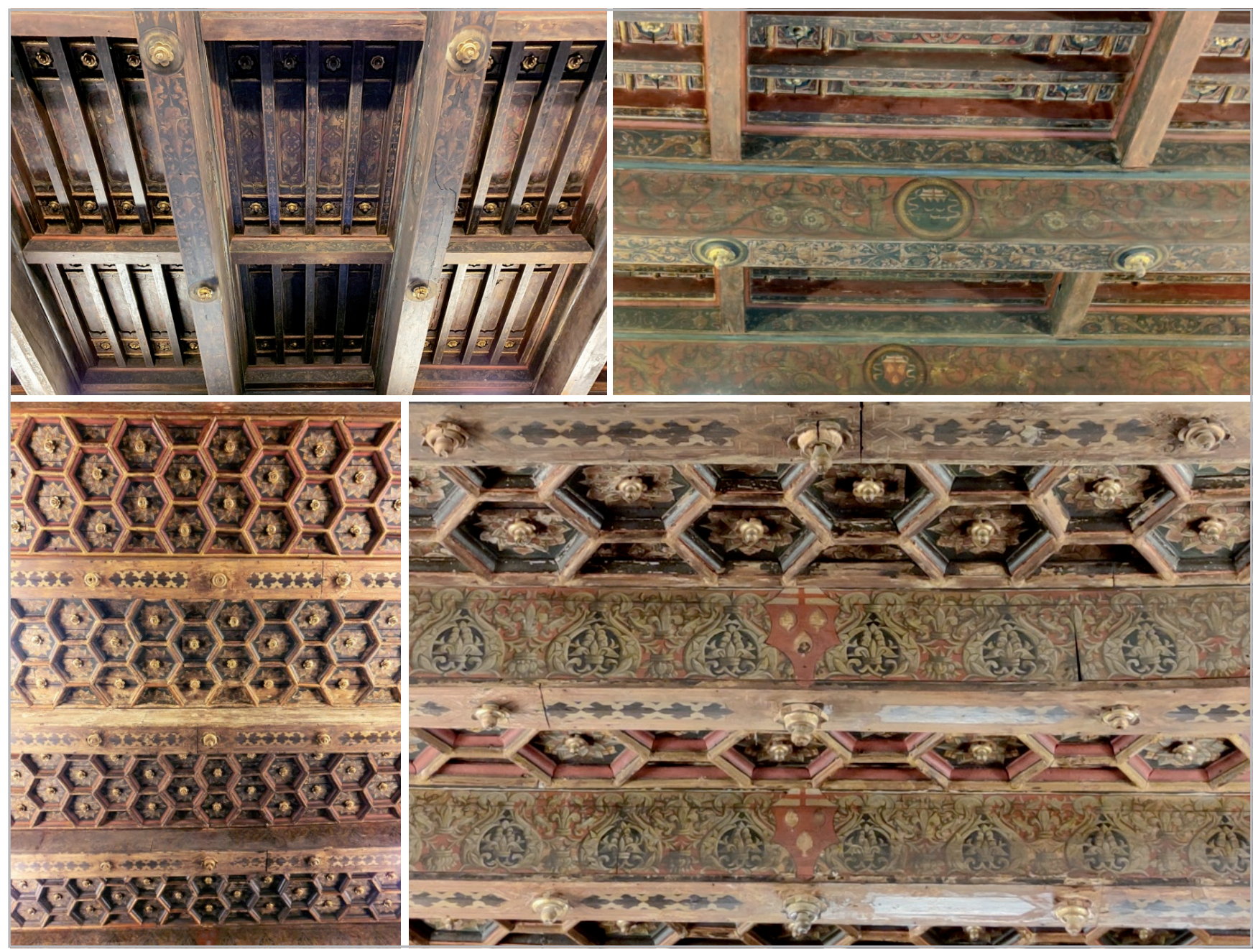

Figura 5.- Techumbres de las salas de la Biblioteca de la Real Academia de Buenas Letras. Fotografías propias. 
Después, el proyecto de Rafael Manzano de agosto de 1973 proponía añadir un artesonado con cuatro faldones inclinados y almizate central, colgado de la estructura de la cubierta. En el capítulo II de las mediciones aparecía:“... artesonado en madera de pino Flandes de primera calidad, perfectamente curada, el cual llevará forma de artesa, tallado con motivos decorativos...."

Sin embargo, la armadura ochavada hoy existente no coincide con dicho diseño. La compra, por parte de Manzano de un lote de artesonados al anticuario Manuel Martín Franco (Madrid) para la masía Mas Olivet en Palau Sator (Gerona)10, posibilitó la obtención de fragmentos usados para la reconstrucción. El propio Manzano ha confirmado que "la caja de escalera es la antigua, pero había perdido su armadura. La que vemos hoy está colocada por mí y reconstruida sobre unos fragmentos que poseía procedentes de un anticuario..." (Manzano 1997) [figura 6].

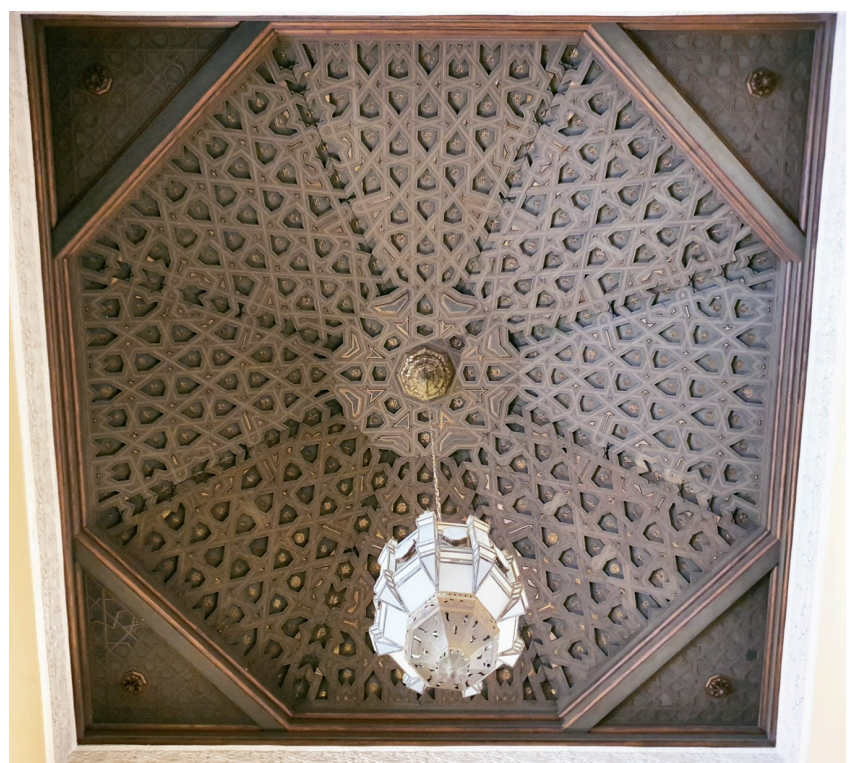

Figura 6.- Artesonado en escalera. Fotografía propia.

\section{- Artesonado de la entreplanta}

“[...] E tiene un saquiçami de nueve y doze con sus deçendidas de lo mismo con sesenta e quatro razimos dorados. E sus çafates. E candilejos dorado e lo otro es pintado. E tiene un arocabe de jeseria a la redonda".

La dependencia que comunica el descansillo de la escalera principal con el entresuelo, hoy Salón de Plenos de la Real Academia de Bellas Artes, conserva el mejor artesonado original del palacio, con los blasones de Pinelo y de la Torre. El alarife describe "un saquiçami de nueve y doze con sus deçendidas". Por "saquiçami" se refiere a un techo ataujerado, no apeinazado como otros del palacio, aunque se aprecia un error en dicha descripción, pues se trata de un artesonado de lazo de ocho y doce, no de nueve y doce. Con el término "deçendidas" se hacía referencia a los cuatro paños perimetrales inclinados [figura 7].
Según la memoria de la tercera fase de las intervenciones de Gómez-Millán, ante las dudas sobre la estabilidad de este artesonado se procedería a su sujeción mediante "la colocación de vigas de hierro de perfiles laminados, para la suspensión del artesonado, incluidos tensores, tornillos y planchuelas."

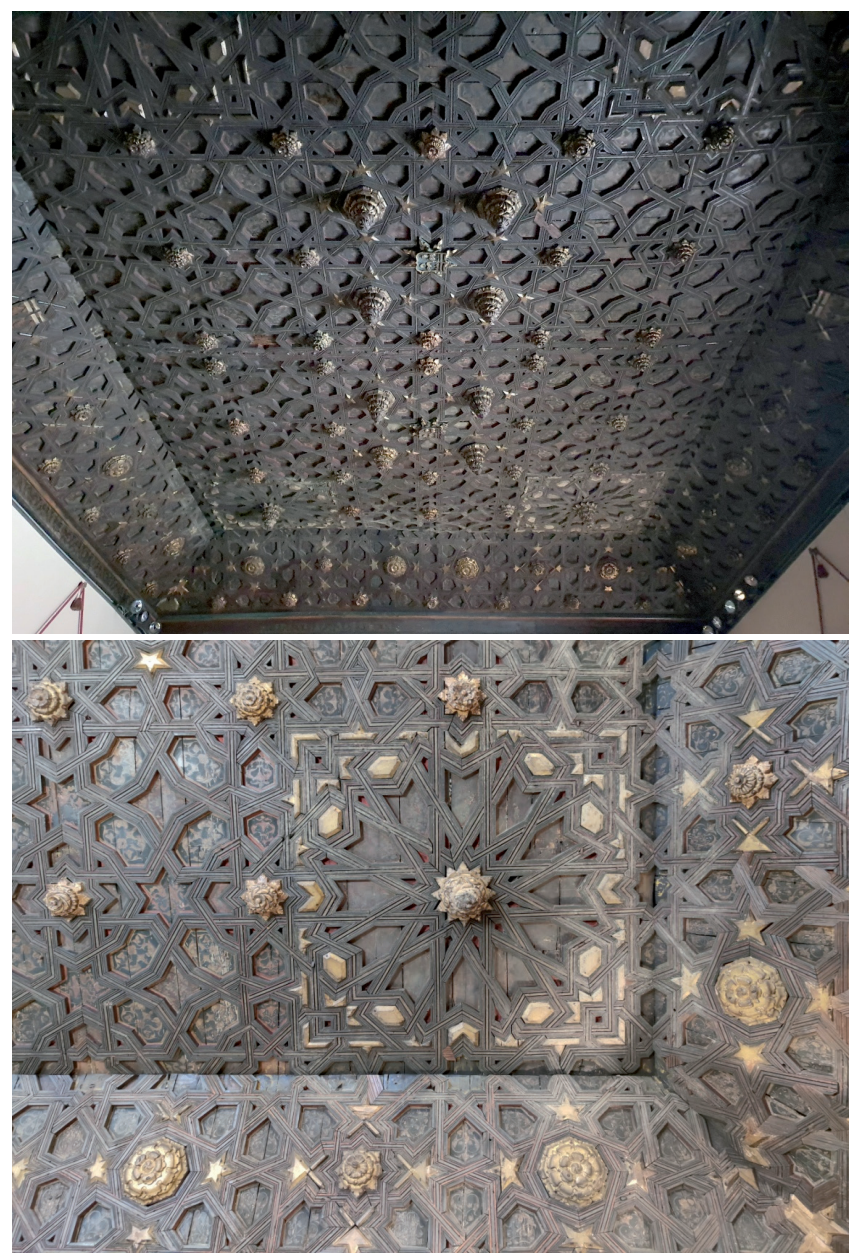

Figura 7.- Artesonado entreplanta. Fotografías propias.

\section{Techumbres planta alta}

\section{- Capilla y antecapilla}

"Yten desta pieça entramos a una recamara que cae sobre la casapuerta la [...] e lo alto es tejado a dos aguas con su albate de lazo de copa cruz con un razimo dorado e ansimismo su guarniçion con sus copas dorados e un arocabe de jeseria"

El artesonado original de la recámara o capilla se ha conservado, a pesar de que en la Pensión Don Marcos la estancia se usó como cuarto de baño. En el proyecto de Manzano de febrero de 1969, se decía que la capilla "muy degradada como toda la casa [...] conserva el artesonado de cubrición, al que le falta la piña de mocárabes que decoraba el centro de su almizate"; y se recogieron partidas presupuestarias para su limpieza y para construir una nueva piña de mocárabe [figura 8]. 

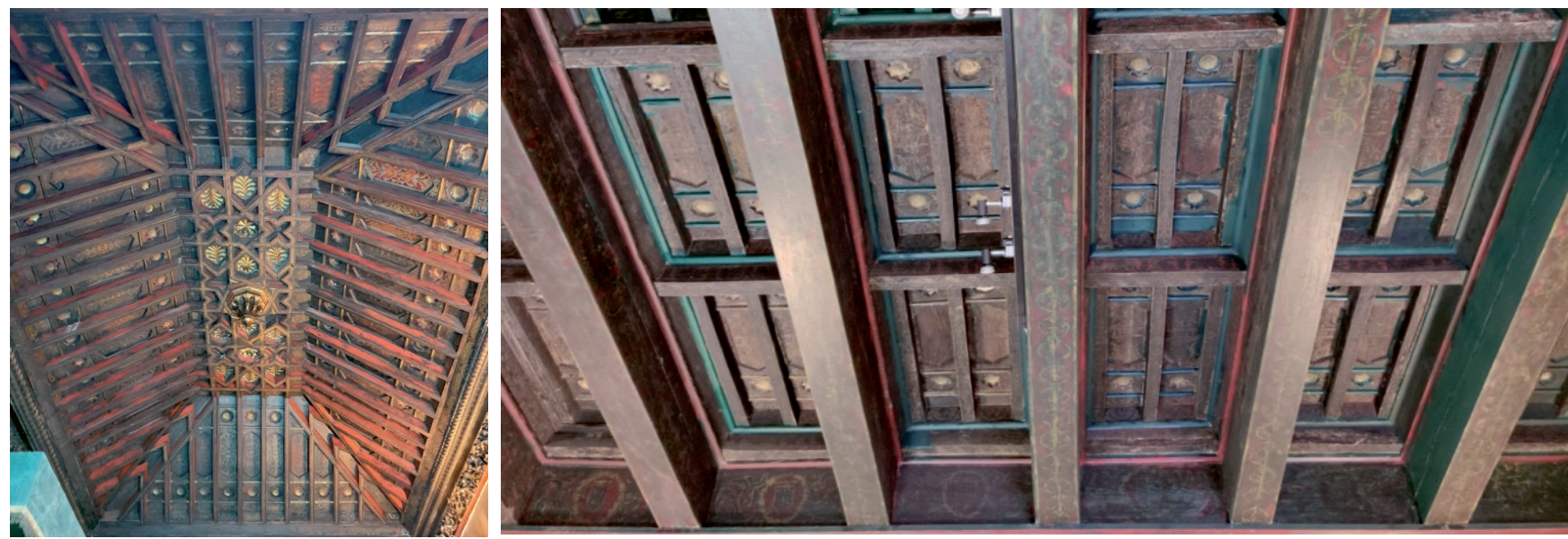

Figura 8.- Techumbres Capilla y Antecapilla. Fotografías propias.

Seguidamente se describe la actual antecapilla, que tenía un desaparecido techo de artesones con florones entablados y dorados:

"Yten desta sala entramos a una camara que cae sobre la casapuerta [...] doblada al mismo tamaño sobre un suelo de artesones con sus florones entablados e dorados e su arocabe de sus vanos e su encadenamiento dorado. E tiene otra de jeseria a la redonda".

Jesús Gómez-Millán pudo observar restos hoy desaparecidos de una "cornisa tallada y dorada", según anotación en uno de sus planos. El proyecto de Manzano de febrero de 1969 decía: "se restaurará un magnífico artesonado de viguería decorada, acoplándolo al techo de la nave"; y en una sección incluida en su proyecto de noviembre de 1978, se recogía en planta alta un artesonado que hoy no existe junto al patio apeadero. Dicho artesonado fue acoplado a la antecapilla. Su traslado ha sido confirmado verbalmente por Rafael Manzano [figura 8].

- Salón de Actos de la Real Academia de Bellas Artes de Santa lsabel de Hungría

"Yten del corredor frontero entramos a una sala que cae sobre la sala por a donde entran a la huerta [...] e lo alto esta tejado a dos aguas sobre sus quinze tijeras e sus almoxairas e alfarxias e tiene sus ladrillos por tabla"

Sobre el Salón de Actos de la Real Academia de Bellas Artes, la memoria del proyecto de Manzano de febrero de 1969 decía: "se han perdido los artesonados de la planta alta, que en la sala del jardín fueron sustituidos por falsas bóvedas encamonadas con yeserías manieristas semejantes a las de las naves bajas de Santa María la Blanca". Se conservan fotos de dicha bóveda del siglo XVII con la decoración preexistente, cuyos motivos fueron reproducidos por Manzano.

El estrado de dicho salón era una sala contigua independiente, con ventana a calle Abades, descrita en el apeo con artesones ochavados, quizás por error, pues la techumbre hoy conservada no es ochavada, aunque sin duda es original del siglo XVI y no se han documentado restauraciones de la misma [figura 9]:

"en esta dicha sala de el postrero portal [...] e lo alto della es tejado un saquiçami. Por debaxo de artesones ochauados pintados e tiene cada una una ventana a la calle".

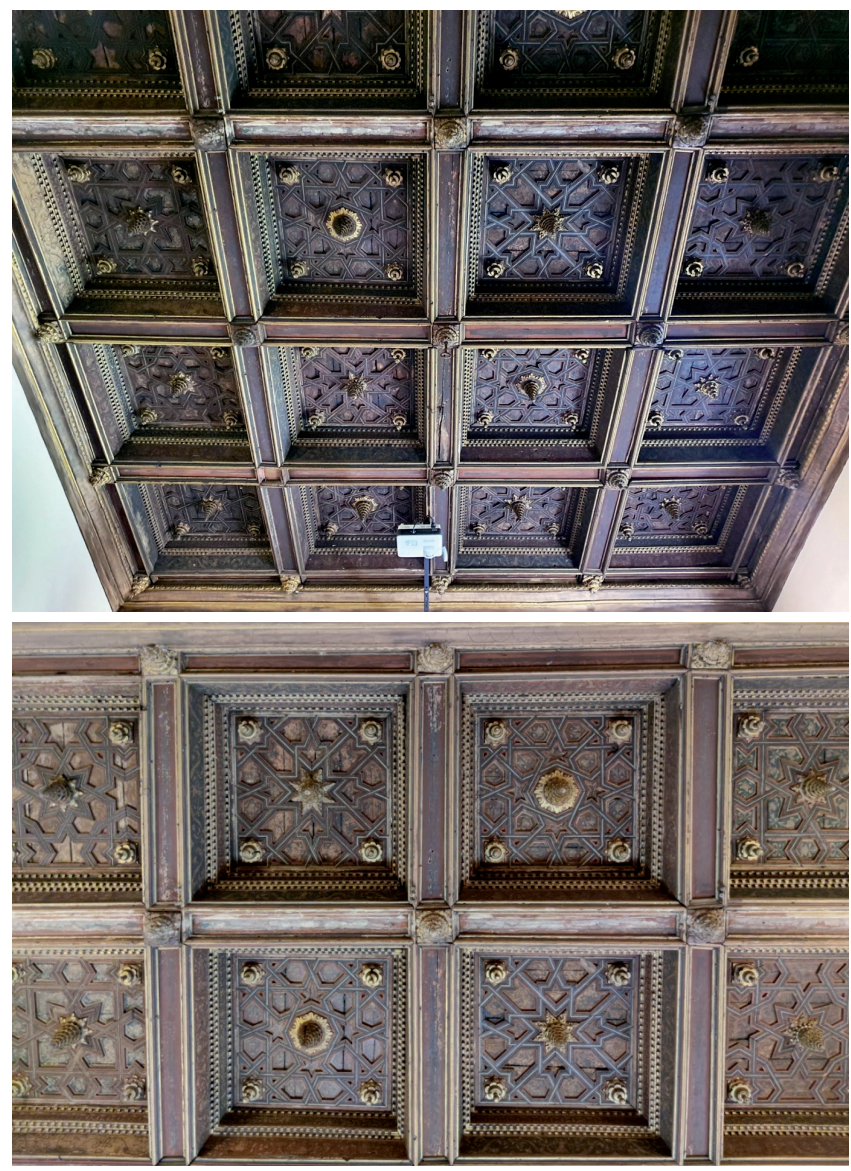

Figura 9.- Techumbre del estrado del Salón de Actos de la Real Academia de Bellas Artes. Fotografías propias. 


\section{- Techumbres desaparecidas en planta alta}

"Yten del corredor primero [...] entramos a una sala que cae sobre el reçebimiento [...]. E lo alto es tejado a dos aguas sobre e con sus limas y el almisate es de lazo con tres pares de tirantes y el almisate con tres razimos los dos razimos y el uno es cubo dorados y en el paño de enmedio tiene seis razimos con otros quatro grandes que tiene las pechinas."

Desde la galería sur se accede a las dependencias altas junto al apeadero, hoy usadas como salas de exposiciones temporales. No se han conservado sus techumbres, sustituidas por forjados de hormigón por Gómez-Millán; salvo una que fue trasladada por Manzano a la antecapilla, según ya se ha indicado.

Especial interés reviste la descripción de techumbres en una dependencia con escalera de acceso a un singular pabellón desaparecido en cubierta, cuya existencia se ha corroborado en fotografías de finales del siglo XIX y principios del XX (Barrero, 2017a). Tenía tejado a cuatro aguas y ventana al patio apeadero. Fue desmontado por Jesús Gómez-Millán en la cuarta fase de sus intervenciones entre septiembre de 1968 y junio de 1969. El apeo de 1542 dice lo siguiente:

"Yten boluiendo a la sala entramos sobre mano ysquierda a una camara que cae sobre la camara del reçebimiento primero [...]. Es lo alto es doblado al mismo tamaño sobre quatro pinos pintados e sus almoxairas e alfarxias. [...] e tiene un escalera". "Yten subimos por esta dicha escalera a una camara que cae sobre la camara que cae sobre la otra camara primera del reçebimiento [...] es tejado a quatro aguas sobre una armadura llana de lima bordon e sus azulejos por tabla blancos e azules e verdes. E tiene su arocabe a la redonda de madera".

Junto a las galerías altas, en las habitaciones con fachada a la calle Abades existían otras techumbres descritas en el apeo que habrían desaparecido cuando Gómez-Millán colocó forjados de hormigón. Además, en el texto del siglo $\mathrm{XVI}$ se detallan dependencias junto al patio-jardín, con techumbres que parecen tener menor relevancia. Estas fueron objeto de importantes transformaciones cuando el palacio se convirtió en pensión y en su mayor parte se sustituirían en el siglo XX.

\section{- Torreón-mirador}

"Yten desta recamara subimos [...] a un tirasol [...] sobre las camaras que caen sobre la casapuerta [...] e lo alto es tejado a dos aguas con sus limas e sobre una armadura llana con tres pares de tirantes e tiene sus azulejos por tabla blanco verde e azul [...]".

Uno de los elementos más emblemáticos de este palacio es el torreón-mirador, denominado tirasol en el apeo, con once arcos sobre columnas de mármol y pretiles de cantería. Al igual que hoy, se accedía a este desde la capilla en planta alta. El primer proyecto de Manzano de febrero de 1969 se centró en su restauración. Se desmontó la armadura ruinosa y se zuncharon las arquerías. Sobre dicho zuncho se reconstruyó la armadura copiando la desaparecida [figura 10]. Después se construyeron forjados metálicos sobre los preexistentes de madera, anclando a esos zunchos las cabezas del nuevo envigado y colgando de este las viejas armaduras.

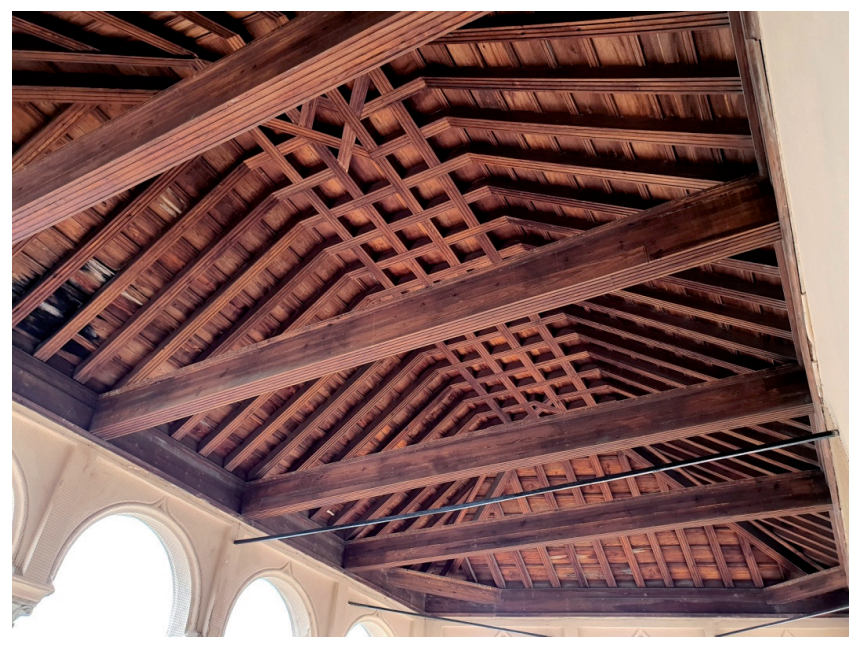

Figura 10.- Techumbre del torreón-mirador. Fotografía propia.

\section{Conclusiones}

En relación con las palabras de Leopoldo Torres Balbás citadas al iniciar este texto, referentes al uso de una adecuada terminología, debe subrayarse la importancia del léxico aportado por el apeo de 1542 como expresión viva y real de suépoca. Aunque el análisis de sus términos no es un objetivo de este trabajo, debe considerarse que sus significados han sido estudiados por Enrique Nuere (Nuere 2000); y en una tesis recientemente publicada sobre la arquitectura doméstica sevillana del siglo XVI que, tras analizar cientos de apeos, aporta un glosario con más de quinientas voces cotejadas con diversas fuentes, diccionarios o tratados (Núñez 2020). Dicho léxico constituye una rica herencia de variada procedencia (romana, medieval islámica o cristiana, mudéjar, renacentista...) que es importante considerar y por ello aquí se ha optado por reproducir gran parte del texto original transcrito.

Tras ofrecer datos generales sobre el palacio de los Pinelo, esta investigación ha desarrollado un recorrido inédito por sus distintas dependencias siguiendo el citado apeo de 1542. Ello ha permitido constatar las techumbres que entonces existían y se han conservado, transformado o desaparecido. Los dibujos y fotografías propias realizados corroboran la fiabilidad del texto, a pesar de sus pequeñas inexactitudes.

Además este trabajo ofrece destacados resultados de una minuciosa indagación sobre las intervenciones y restauraciones acometidas como consecuencia del precario 
estado de conservación del palacio a mediados del siglo XX. Se han revisado todas las obras realizadas por el arquitecto municipal Jesús Gómez-Millán (1967-1971) y por Rafael Manzano Martos (1969-1981), bajo la Dirección General de Bellas Artes, para alojar la sede de las Reales Academias de Buenas Letras y de Bellas Artes de Santa Isabel de Hungría.

Jesús Gómez-Millán acometió nueve fases de intervenciones desconocidas hasta tal punto que en la única monografía que existe sobre este palacio (Falcón 2006) las atribuye a otro destacado arquitecto sevillano de nombre parecido, José Gómez Millán. Aunque en el título de sus proyectos se decía que eran obras de consolidación, parece más adecuado considerarlas como intervenciones que alteraron un edificio declarado monumento. Se sustituyeron gran parte de las techumbres de planta alta que presentaban un avanzado deterioro por forjados de hormigón. Se transformaron algunas cubiertas con nuevos criterios formales, desmontando pabellones en el apeadero y en el jardín, y elevando el tejado de la escalera principal. Además, se forraron con maderas, de forma discreta, los nuevos forjados de hormigón en la galería superior del patio; y se acometió la consolidación estructural del artesonado de la entreplanta.

Rafael Manzano afrontó más diversas y versátiles restauraciones, a partir de un proyecto unitario en 1970 para Museo Histórico de la Ciudad, y otro posterior para la actual sede de las Reales Academias. Consolidó todos los forjados del primer nivel del palacio, reconstruyendo con hormigón solo aquellos en los que no había decoración. Procedió a colgar de estructuras metálicas las techumbres que no reunían condiciones resistentes, en el entorno del patio apeadero, en la galería del patio o bajo la torre-mirador. En el salón de actos de la Academia de Buenas Letras, donde solo quedaban el friso de yesería y las vigas maestras, se diseñaron nuevos fondos ataujerados con trazas de inspiración mudéjar. En el salón de actos de la Academia de Bellas Artes, se acometió una restitución filológica de su antigua bóveda de bajorrelieves del siglo XVII, copiada de restos existentes. En la actual Secretaría de Buenas Letras, cuya techumbre había desaparecido, se construyó un nuevo techo usando como modelo la bóveda original del pasillo próximo, que siguió la lámina LXXV vta. del libro IV de Serlio. La armadura perdida de la escalera principal se reconstruyó a partir de fragmentos procedentes de anticuario. Para cubrir la actual antecapilla se trasladó el alfarje situado bajo el antiguo pabellón del apeadero, cuyas salas adyacentes habían perdido sus techumbres y resultaba menos acorde con la nueva zona expositiva prevista. También reconstruyó la armadura del torreón, copiando la desaparecida, que encontró en estado ruinoso. Además realizó una cuidadosa limpieza de elementos constructivos que no necesitaron restauración alguna.

Además de analizar las principales techumbres del palacio, para ilustrar su rica diversidad, se han aportado plantas generales del estado actual junto a nuevas fotografías. A partir de todo ello, futuros trabajos podrán profundizar en sus relaciones con las techumbres de otros palacios de aquel tiempo, o con otras tipologías edificatorias.

Hasta ahora la mayor parte de los estudios sobre la Casa de los Pinelo habían centrado su atención en su patio de honor y en sus singulares arquerías. A partir de esta investigación las bellas techumbres de este palacio renacentista deben considerarse como un destacado símbolo de su identidad arquitectónica.

\section{Notas}

[1] Archivo Catedral Sevilla, A.C.S. Sección IV, Fábrica. Libro no 377. Fol. CCXCV-CCCII vto.

[2] Archivo Municipal Sevilla (AMS). Licencias de obras. Lib.28. Ca.1. № 109.

[3] AMS. Expediente Obras de Particulares. 1.018/1942.

[4] AMS. Comisión Administradora del Impuesto para la Prevención del Paro Obrero. Expedientes 19/1967. D/1368 (fase 1); 38/1967. D/1369 (fase 2); 32/1968. D/1371 (fase 3); 41/1968. D/1371 (fase 4); 25/1969. D/1373 (fase 5); 42/1969. D/1374 (fase 6); 11/1970. D/1375 (fase 7); 31/1970. D/1376 (fase 8); 10/1971. D/1376 (fase 9).

[5] Archivo General de la Administración (AGA). Signatura caja: 70.869; Signatura BIC: ME/06/00/070869.

[6] AGA: 70.648. Signatura BIC: ME/00/00/070648.

[7] AGA: 70.765. Signatura BIC: ME/04/00/070765.

[8] AGA: 70.793. Signatura BIC: ME/03/00/070793.

[9] AGA: 95.682. Signatura BIC: ME/00/00/095682.

[10] Archivo privado Rafael Manzano. Proyecto 1425, “Casa de payés en Mas Olivet".

\section{Referencias}

ALMAGRO GORBEA, A., MANZANO MARTOS, R. (2008). Palacios medievales hispanos [Discurso del Académico Electo de A. Almagro y contestación de R. Manzano]. Madrid: Real Academia de Bellas Artes de San Fernando. http://hdl.handle.net/10261/19801

BARRERO ORTEGA, P. (2017a). La Casa de los Pinelo. Las transformaciones de un palacio renacentista en el siglo XX [tesis doctoral inédita]. Sevilla: Universidad de Sevilla. http://hdl.handle. $\underline{\text { net/11441/63987 }}$

BARRERO ORTEGA, P. (2017b). Las transformaciones arquitectónicas de la Casa de los Pinelo en Sevilla entre 1885 y 1981, Temas de Estética y Arte, XXXI: 153-172. 
BARRERO ORTEGA, P.; GÁMIZ GORDO, A. (2020a). The Casa de los Pinelo in Seville according to a text from 1542. En: Graphical Heritage. EGA 2020, Cham: Springer, 163-165, https://doi: 10.1007/978-3-030-47979-4 15

BARRERO ORTEGA, P.; GÁMIZ GORDO, A. (2020b). La Pensión Don Marcos en el palacio de los Pinelo (Sevilla, 1885-1964). Quiroga. Revista de patrimonio iberoamericano, 18: 24-37. https://doi. org/10.30827/quiroga.v0i18.0002

CUESTA SALADO, J. (2017). El seguimiento de los modelos de Serlio en los artesonados del sur de Tierra de Campos y el maestro de carpintería Alonso de Porquera. BSAA arte, 83: 71-102. https:// doi.org/10.24197/bsaaa.83.2017.71-102

FALCÓN MÁRQUEZ, T. (2006). La Casa de Jerónimo Pinelo sede de las R.R.A.A sevillanas de Buenas Letras y de Bellas Artes. Sevilla: Fundación Aparejadores y Fundación Cruzcampo.

LÓPEZ GUZMÁN, R. J. (2012). Carpintería mudéjar en América. En: La carpintería de armar: técnica y fundamentos histórico-artísticos, Málaga: Universidad de Málaga, 17-44.

MANZANO MARTOS, R. (1997). La Casa de los Pinelo y los palacios sevillanos del siglo XVI [Discurso de apertura del curso académico 1996/97]. Boletín de la Real Academia Sevillana de Buenas Letras. Minervae Baeticae 25: 7-20. http://hdl.handle.net/11441/14695

MANZANO MARTOS, R. (2019). Mudéjar, gótico y renacimiento en la Casa de los Pinelo [Discurso de inauguración del curso académico 2018-2019]. Boletín de Bellas Artes [Sevilla], XLVII, 1924.

NUERE MATAUCO, E. (2000). La carpintería de armar española. Madrid: Ediciones Munilla Leira.

NUERE MATAUCO, E.; MANZANO MARTOS, R. (2010). Dibujo, geometría y carpinteros en la arquitectura [Discurso del Académico Electo de E. Nuere y contestación de R. Manzano]. Madrid: Real Academia de Bellas Artes de San Fernando. https://cutt.ly/ ufJO6fN

NÚÑEZ GONZÁLEZ, M. (2020). Arquitectura, dibujo y léxico de alarifes en la Sevilla del siglo XVI. Casas, corrales, mesones y tiendas. Sevilla: Editorial Universidad de Sevilla, Fundación Focus.

NÚÑEZ GONZÁLEZ, M. (2018). The Role of Drawing and Master Alarifes in the Study of the Sixteenth and Seventeenth Centuries Sevillian Housing from Graphical and Literary Documents. En: Graphic Imprints. EGA 2018, Cham: Springer, 685-698. https://doi. org/10.1007/978-3-319-93749-6 55

RAFOLS, J. F. (1926). Techumbres y artesonados españoles. Barcelona: editorial Labor.

TORRES BALBÁS, L. (1944). El más antiguo alfarje conservado en España. Crónica Arqueológica de la España Musulmana XV, AlAndalus, IX, 2, 348-359. http://oa.upm.es/34133/

\section{Autor/es}

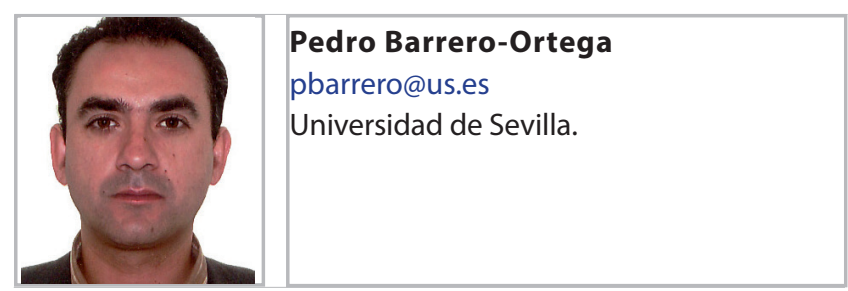

Pedro Barrero Ortega es Doctor Arquitecto y Profesor Asociado de la Universidad de Sevilla. Su tesis doctoral se centró en La Casa de los Pinelo (2017). Su extensa actividad profesional se ha desarrollado durante décadas, junto a Rafael Manzano Martos, en variadas intervenciones en patrimonio arquitectónico. Es autor de diversos artículos en dicho ámbito desde el punto de vista de la expresión gráfica arquitectónica. https://orcid.org/0000$\underline{0002-0751-8713}$

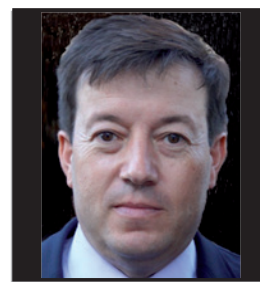

\section{Antonio Gámiz-Gordo}

antoniogg@us.es

Universidad de Sevilla.

Doctor Arquitecto y Profesor Titular del Departamento de Expresión Gráfica Arquitectónica en la Universidad de Sevilla. Desde 2015 es responsable del grupo de investigación "HUM976. Expregráfica. Lugar, Arquitectura y Dibujo". Es autor de numerosos libros, artículos y contribuciones en congresos, sobre dibujo y análisis de la arquitectura, patrimonio, ciudad, paisaje e imágenes a lo largo de la historia. https://orcid. org/0000-0001-6188-3167

Artículo enviado el 21/09/2020 Artículo aceptado el 06/11/2020

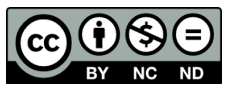

https://doi.org/10.37558/gec.v18i1.843 